\title{
A política de Inclusão do Governo brasileiro a partir dos editais públicos de Extensão-ProExt
}

\section{The Brazilian Government's Inclusion Policy from the Extension of Public Announcements - ProExt}

Silvia Pimentel, Lucia Tinoco, Dalmir Pacheco

Instituto Federal de Educação, Ciência e Tecnologia do Amazonas - IFAM

\begin{abstract}
Resumo
O Brasil tem definido políticas públicas e criado instrumentos legais que garantem os direitos das pessoas com necessidades especiais, para tal passou por varias etapas que justificam sua chegada às leis $\mathrm{e}$ editais de inclusão, particularmente para o ensino tecnológico. $\mathrm{O}$ presente artigo objetiva descrever a primeira etapa da pesquisa intitulada A política de Inclusão do Governo brasileiro a partir dos editais públicos de Extensão-ProExt, "Programa de extensão Universitária". Para tanto será utilizada a pesquisa bibliográfica. Diante disso, justifica-se a relevância deste estudo, como relato de uma iniciativa reflexiva fundamentada no princípio do direito ao exercício pleno da cidadania.

Palavras-chave: movimentos sociais, Leis de Inclusão, Editais PROEXT.
\end{abstract}

\begin{abstract}
Brazil has set public policies and created legal instruments that guarantee the rights of persons with special needs, such went through various stages that justify their arrival to the laws and edicts inclusion, particularly for technology education. This article aims to describe the first stage of the research entitled "Inclusion policy of the Brazilian government from public tenders Extension-PROEXT" University Extension Program ". Therefore the literature will be used. Therefore, justified the relevance of this study, as reported in a reflective initiative based on the principle of the right to full citizenship
\end{abstract}

Keywords: social movements, Inclusion Laws, Notices PROEXT.

\section{Os movimentos sociais no Brasil}

Logo após ser implantada a República (1889), têm início os movimentos chamados de "associativismo".

A partir de meados do século XX, é possível observar o surgimento de organizações criadas e geridas pelas próprias pessoas com deficiência. A motivação inicial é a solidariedade entre pares nos seguintes grupos de deficiência: cegos, surdos e deficientes físicos que, mesmo antes da década de 1970, já estavam reunidos em organizações locais com abrangência que raramente ultrapassava o bairro ou o município, em geral, sem sede própria, estatuto ou qualquer outro elemento formal. Eram iniciativas que visavam ao auxílio mútuo e à sobrevivência, sem objetivo político prioritariamente definido. Essas organizações, no entanto, constituíram o embrião das iniciativas de cunho político que surgiriam no Brasil, sobretudo durante a década de 1970. (LANNA JÚNIOR, 2010, pág. 28).

Partindo deste momento de "associativismo" que proporcionou as pessoas com alguma deficiência a convivência com seus pares os movimentos crescem.

As pessoas com deficiência, antes restritas à caridade e a políticas de assistência, agora caminham em direção às conquistas no universo da política e da luta por seus direitos. Esse processo de associações criou o ambiente para a formalização da consciência que resultaria no "movimento político das pessoas com deficiência" na década de 1970. Nessa época, surgiram as primeiras organizações compostas e dirigidas por pessoas com deficiência, contrapondo-se às associações que prestavam serviços a este público. Essa contraposição proporcionada pela convivência entre os pares, leva às discussões e debate sobre as dificuldades encontradas e possíveis soluções para as mesmas, desencadeando movimentos em prol dos seus direitos. A partir daí, as pessoas com deficiência passam a serem agentes ativos e políticos na busca por transformação na sociedade.

Durante a ditadura (1964-1985), esses movimentos ficaram adormecidos, porém ao seu término voltaram reorganizados e com a ativa participação da sociedade civil. Afirma LANNA JÚNIOR (2010) que os movimentos sociais, antes silenciados pelo autoritarismo, ressurgiram. Vários setores da sociedade gritaram com sede e com fome de participação: negros, mulheres, índios, trabalhadores, sem-teto, sem-terra e, também, as pessoas com deficiência.

Neste sentindo, os novos movimentos sociais, inclusive os das pessoas com deficiência, saem do anonimato e formam novas organizações, articulam-se nacionalmente, criando assim estratégias de luta para reivindicar igualdade de oportunidades e garantia de seus direitos.

Para Vieira (2004), a função dos movimentos sociais não é o exercício do poder, mas lutar pela delimitação e orientação da ação do poder estatal, para que esse cumpra as tarefas para as quais existe como instituição, que é a responsável por gerir as necessidades objetivas dos 
cidadãos, devendo desempenhá-las a partir do interesse coletivo.

\section{As leis de caracterização dos editas}

O processo dos movimentos sociais se reflete na Constituição Federal promulgada em 1988. A Assembleia Nacional Constituinte (1987-1988), envolvida no espírito dos novos movimentos sociais, foi a mais democrática da história do Brasil, com canais abertos e legítimos de participação popular. A partir da década de 1990, os documentos oficiais do Brasil passam a ter em seu conteúdo a necessária mudança na escolarização das pessoas com alguma deficiência. A partir da LDB, a educação especial torna-se modalidade de ensino.

A Lei n. 9394/96, que estabeleceu as Diretrizes e Bases da Educação Nacional, em seu Artigo 59, determina que os sistemas de ensino assegurem aos educandos com necessidades especiais, entre outros aspectos: currículos, métodos, técnicas, recursos educativos e organização específicos, para atender às suas necessidades, bem como terminalidade específica para aqueles que não puderem atingir o nível exigido para a conclusão do ensino fundamental, em virtude de suas deficiências (MELETTI, 2010, p.2).

Ao tornar-se uma modalidade de ensino, as políticas, que vão se estabelecendo, são voltadas para inclusão desse alunado. Assim temos uma serie de direcionamentos legais para essa população na rede regular de ensino.

Em 2002, a Resolução CNE/CP n ${ }^{\circ} 1 / 02$, estabeleceu as Diretrizes Curriculares Nacionais para a Formação de Professores da Educação Básica, definindo que as instituições de ensino superior devem prever, em sua organização curricular, formação docente voltada para a atenção à diversidade e que contemple conhecimentos sobre as especificidades dos alunos com necessidades educacionais especiais.

Visando impulsionar a inclusão educacional e social, são regulamentadas as Leis n. 10048/00 e 10098/00 pelo Decreto n. 5296/04 pelo governo federal, a fim de promover a acessibilidade das pessoas com deficiência ou com mobilidade reduzida, e para tal, é criado o Programa Brasil Acessível pelo Ministério das Cidades, a fim de promover a acessibilidade urbana e apoiar ações que garantam o acesso universal aos espaços públicos. (BRASIL, 2010).

Neste Sentido ficam garantidas as pessoas com necessidades especiais o exercício pleno da cidadania e o seu lugar no espaço escolar básico e universitário.

\section{Leis, conceitos e descrição dos editais ProExt}

De acordo com o Pano Nacional de Extensão, No fim dos anos 1950, início dos anos 1960, os estudantes universitários brasileiros, organizados na União
Nacional dos Estudantes - UNE, empreenderam movimentos culturais e políticos reconhecidos como fundamentais para a formação das lideranças intelectuais de que carecia o país. Estavam assim definidas as áreas de atuação extensionista, antes mesmo que o conceito fosse formalmente definido.

A Política Nacional de Extensão é pactuada pelas Instituições Públicas de Ensino Superior (IPES), reunidas no FORPROEX, tendo como documento referencial o Plano Nacional de Extensão, publicado em novembro de 1999. O Plano estabelece o seguinte:

“A Extensão Universitária é o processo educativo, cultural e científico que articula o Ensino e a Pesquisa de forma indissociável e viabiliza a relação transformadora entre a Universidade e a Sociedade."

O Programa de Extensão Universitária - ProExt tem o objetivo de apoiar as instituições públicas de ensino superior no desenvolvimento de programas ou projetos de extensão que contribuam para a implementação de políticas públicas.

Criado em 2003, o ProExt abrange a extensão universitária com ênfase na inclusão social.

O decreto $n^{\circ} 6.495$, de 30/06/2008 - Institui o Proext. Lei $n^{\circ} 12.155$, de 23/12/2009 - Dispõe sobre a concessão de Bônus Especial de Desempenho Institucional BESP/DNIT e dá outras providências (institui a concessão de bolsas de extensão).

Decreto $n^{\circ} 7.416$, de 30/12/10 - Regulamenta os art. 10 e 12 da lei $\mathrm{n}^{\circ} 12.155$, de 23 de dezembro de 2009, que tratam da concessão de bolsas para desenvolvimento de atividades de ensino e extensão universitária.

\section{As ações de Extensão}

As ações de extensão são divididas e, programas e projetos. Os programas comtemplam as ações processual e continuada de caráter educativo, social, cultural, cientifico ou tecnológico, com objetivo especifico e prazo determinado. Os projetos podem ser vinculados a um programa ou projeto isolado.

\section{Temas desenvolvidos pelo ProExt}

1 atenção integral à família;

2 combate à fome;

3 erradicação do trabalho infantil;

4 combate ao abuso e à exploração sexual de crianças e adolescentes;

5 juventude e desenvolvimento social;

6 geração de trabalho e renda em economia solidária;

7 promoção e/ou prevenção à saúde;

8 violência urbana;

9 direitos humanos;

10 educação de jovens e adultos;

11 atenção à pessoa idosa, à pessoa com deficiência e às populações indígenas e quilombolas;

12 atividades complementares ao Programa Brasil Alfabetizado;

13 educação ambiental e apoio ao desenvolvimento comunitário; 
14 inclusão étnica;

15 apoio à organização e desenvolvimento comunitário; 16 inclusão social dos usuários de drogas;

17 inclusão digital;

18 apoio às atividades de escolas públicas;

19 ensino de ciências;

20 Educação de jovens e adultos, incluindo apoio ao desenvolvimento de sistemas locais e regionais de educação, alfabetização e letramento.

As IES podem apresentar nesta linha temática dois programas e dois projetos.

\section{A linha temática 1 - Educação}

As propostas apresentadas nesta linha temática devem seguir os marcos legais estabelecidos pelo Ministério da Educação - MEC, o qual reuni as principais referencias normativas vigentes para educação no Brasil. Todas as propostas de extensão que envolvam formação de professores devem ser articuladas com a Rede Nacional de Formação Continuada dos Profissionais do Magistério da Educação Básica Pública, instituída pela portaria MEC $\mathrm{n}^{\mathrm{o}} 1.328$, de 23 de setembro de 2011. E ainda seguir os marcos legais nacionais e internacionais, em especial os Eixos Orientadores, Diretrizes e Objetivos do Plano Nacional de Educação em Direitos Humanos e do Programa Nacional de Direitos Humanos 3 (PNDH-3), o qual representa um roteiro para seguirmos o qual garante a consolidação da democracia e garantindo o dialogo permanente entre o estado e a sociedade civil.

Esta linha temática possui 18 subtemas que são: Educação de jovens e adultos, juventude, Educação escolar indígena, Educação escolar quilombola, Educação para Relações Étnico-raciais, Educação do Campo, Educação em direitos humanos, Educação Socioambiental, Educação Especial na Perspectiva Inclusiva, Saúde na escola, Educação Integral e Intersetorialidade, $\mathrm{O}$ Ensino Médio Integrado à Educação Profissional - Condições de participação, Educação infantil, Apoio à Gestão de Redes de Educação Públicas, Apoio à Gestão da Rede de Educação Profissional e Tecnológica - EPT. Condições de participação, Formação de trabalhadores, Apoio ao Pacto Nacional pela Alfabetização na Idade Certa ou Apoio aos processos de alfabetização e letramento, Educação para adolescentes em cumprimento de medidas socioeducativas.

O subtema escolhido para a pesquisa foi - Educação Especial na Perspectiva Inclusiva. Que comtempla.

a) Formação para agentes comunitários, educadores populares, gestores e demais profissionais para organização do espaço escolar, do Projeto Político Pedagógico e Currículo, no sentido de alinhar todas as possibilidades para que a escola e seus atores tenham condições necessárias de atender a todos;

b) Formação de agentes comunitários, educadores populares e profissionais em Língua Brasileira de Sinais - Libras; c) Formação de educadores populares em Braille como ferramenta de acessibilidade à leitura e à escrita; d) Pesquisa-ação para o desenvolvimento da educação bilíngue para estudantes surdos no ensino regular;

e) Pesquisa-ação para o desenvolvimento de ações intersetoriais para a eliminação das barreiras que impedem o acesso e permanência de pessoas com deficiência na escola;

f) Formação de educadores populares para a difusão e uso pedagógico dos recursos de Tecnologia Assistiva para eliminação de barreiras e promoção de autonomia aos estudantes com deficiência, no contexto escolar.

g) Formação de profissionais para a produção de materiais didáticos e pedagógicos acessíveis;

h) Formação de educadores populares para a prática da educação física na perspectiva da educação inclusiva.

i) Formação de agentes comunitários, educadores populares e profissionais sobre técnicas de orientação e mobilidade.

j) Formação de educadores populares para o atendimento educacional especializado de estudantes com deficiência.

\section{Considerações}

Nesta primeira etapa, foi desenvolvida a pesquisa bibliográfica e a escolha da linha temática a fazer parte da pesquisa, a abordagem histórica dos movimentos sociais, que possibilitou a união e por consequência a discursão entre os pares em suas lutas por seus direitos. As leis, que comtemplam a inclusão das pessoas com deficiência, tanto no campo escola quanto do trabalho, sendo possível exigência perante o estado. E uma parte do edital ProExt, demonstrando suas especificidades e apontando a linha temática a qual será desenvolvida a pesquisa. Sendo assim, a primeira etapa da pesquisa esta concluída e a segunda etapa em andamento.

\section{Referencias}

BRASI, Marcos Político-Legais da Educação Especial na Perspectiva da Educação Inclusiva. Ministério da Educação, Secretaria de Educação Especial. Brasília: SECADI, 2010.

LANNA JÚNIOR, MÁRIO Cléber Martins (Comp.). História do Movimento Político das Pessoas com Deficiência no Brasil. - Brasília: Secretaria de Direitos Humanos. Secretaria Nacional de Promoção dos Direitos da Pessoa com Deficiência, 2010. 443p. : il. 28X24 cm. MELETTI, Sílvia Márcia Ferreira; BUENO, José Geraldo Silveira. Escolarização de alunos com deficiência: uma análise dos indicadores sociais no Brasil (1997-2006). In: 33 ${ }^{a}$ Reunião Anual da ANPED, 2010, Caxambú. Educação no Brasil: o balanço de uma década, 2010. p. 1-17.

VIEIRA, LUIZ VICENTE. Os movimentos sociais e o espaço autônomo do "Político": o resgate de um conceito a partir de Rousseau e Carl Schmitt. Porto Alegre: EDIPUCRS, 2004, (col. Filosofia - 167).

Programa Nacional de Direitos Humanos (PNDH-3) / Secretaria Especial dos Direitos Humanos da Presidencia da República - ver. Atual, Brasilia: SEDH/PR, 2010. 